\title{
Myracetyma piraya SP. NOV. (COPEPODA, ERGASILIDAE) DAS BRÂNQUIAS DE Pygocentrus nattereri (KNER, 1860) (CHARACIFORMES: SERRASALMIDAE) DA AMAZÔNIA BRASILEIRA.
}

\author{
José Celso O. MALTA ${ }^{1}$
}

\begin{abstract}
RESUMO - Myracetyma piraya sp. nov. é proposta. Os especimens foram coletados dos lilamentes hranquais de P'ygocentrus nattereri (KNER, 1860)). A espécie nova ditere das outras, no tamanho. no formato do celalotorax, nas extensões cuticulares da antena e no formato e ornamentações dos ramos das permas.
\end{abstract}

Palavas-chave: Copepoda. Lrgasilidac. especie-nova. 1/yracetyma. Amazonia

Byracetyma piraya sp no (Copepoda. Ergasilidae) from the gill of Pygocentrus nattereri (Kner, $180(1)$ (Chatactormes fierrasalmidae) from the Brazilian Amazon.

ABSTRACT Myractymu piraw sp. nov, is proposed. The specimens were cullected from the gill filaments of Pygrecentrus uattereri (Kner. 186(1)). The new species difters from the others, in size, and shape of the eqphalothorax. $\Lambda 1 s 6$. in the euticular extensions of the antenna and the rami of the legs have diflerent shapes and ornamentations.

Key-words: Copepoda, Ergasilidac. new specie. Myracetyma, Amazônia.

\section{INTRODUÇÃO}

Atualmente são conhecidas cerca de 1570 espécies de copépodos da ordem Poecilostonatoida. inchuidas em 47 famílias e sete gêneros sem famílias definidas. Exceto cinco familias (Corycaeidae, Oncaeidae, Paralubbockiidae. Sapphirinidae e Urocopiidac) cujos representantes säo na maioria planctônicas, a grande manoria dos membros desta ordem é simbionte de invertebrados marinhos c/ou peixes de água doce (HO, 1991)

A aparente origem monofilética das três famílias com representantes na água doce, indica que os poecilostomatóideos tiveram uma única bem sucedida invasão na água doce. A Amazonicopeidae e a Vaigamidae são conhecidas apenas de peixes da bacia Amazônica. mas a Ergasilidae é cosmopolita, ocorrendo tanto $\mathrm{em}$ peixes de água doce quanto salgada. A Ergasilidae é a maior destas três familias poecilostomatóideas, possui cerca de 130 espécies com 23 delas ocorrendo em peixes estuarinos ou da costa. A julgar pela posição na árvor filogenética, a hipótese é que estas 23 espécies representam um grupo de ergasilideos secundariamente derivados da existência marinha (HO, 1991).

$\mathrm{Na}$ região Neotropical são conhecidos seis gêneros da família Ergasilidae: Ergasilus Nordmann, 1832: Acusicola Cressey, 1970, 1984;

1 Instituto Nacional de Pesquisas da Amazônia, Coordenação de Pesquisas em Biologia Aquática, Caixa Postal 478, 69011-970, Manaus, Amazonas, Brasil. 
Thatcher, 1984; Brasergasilus, That cher \& B oeger, 1983 : Amplexibranchius Thatcher\& Paredes, 1985; Rhinergasilus Boeger \& Thatcher, 1988 e Myracetyma Malta, 1993 (Thatcher, 1991; Malta, 1992).

MALTA (1992) trabalhando com os copépodos parasitas de brânquias dos peixes da bacia do rio Madeira (estado de Rondônia) encontrou quatro gêneros e cerca de 10 espécies, todos da família Ergasilidae. VARELLA (1992) trabalhando na mesma região, com os copépodos parasitas das fossas nasais, encontrou que $57 \%$ das espécies eram da familia Ergasilidae, $42 \%$ da Vaigamidae e $1 \%$ da Lernaeidae.

Myracetyma piraya sp. $\mathrm{n}$. é a terceira espécie do gênero a ser descrita e a $24^{\text {a }}$ representante da família Ergasilidae na região Neotropical. Foi coletada dos filamentos branquiais de Pygocentrus nattereri (KNER, 1860) no Rio Mamoré, um dos rios formadores do rio Madeira, o segundo maior afluente do rio Amazonas.

\section{MATERIAL E MÉTODOS}

O material estudado neste trabatho foi coletado no estado de Rondônia, região noroeste do Brasil, durante o periodo de 28 de novembro de 1983 a 25 de setembro 1985 .

Os peixes foram identificados, pesados e medidos e as brânquias e vísceras foram removidas e fixadas em formal $10 \%$.

Os copépodos foram retirados dos filamentos brânquias utilizando finos estiletes, microscópio estereoscópio e fixados em formol $5 \%$. Lâminas permanentes, com montagem total dos copépodos, foram preparadas usando o método de Thatcher, denominado "HYP" (publicado em Monoculus, n. 15). Cada individuo foi retirado da solução aquosa (formol 5\%) e mantido em álcool $70 \%$. A seguir, colocados em solução corante, Eosina e Orange-G. Posteriormente colocados em fenol para diafanizar, desidratar e descolorir o excesso. Em seguida colocados em salicilato de metila, para interromper o processo de descoloração. Finalmente, foram montados em bálsamo do Canadá entre lâmina e lamínula e colocados em estufa à $70^{\circ} \mathrm{C}$.

Os desenhos e medidas foram feitos com o auxílio de "câmara clara" e ocular micrométrica, acopladas a um microscópio óptico. Todas as medidas estão expressas em micrômetros.

Os peixes foram depositados na Coleção Ictiológica do Instituto Nacional de Pesquisas da Amazônia, em Manaus.

Os tipos foram depositados nas coleções do Instituto Nacional de Pesquisas da Amazônia (INPA-CR), Manaus, Amazonas e Museu de Zoologia da Universidade Federal de São Paulo, (MZUSP).

\section{RESULTADOS}

Ergasilidae Nordmann, 1832

Acusicolinae Thatcher, 1984

Myracetyma piraya sp. $\mathrm{n}$.

(Figs. 1 - 11)

Material examinado:

Holótipo: fềmea (INPA-CR 606), 
dos filamentos branquiais de Pygocentrus nattereri, coletado no Rio Mamoré, próximo a Surpresa $\left(11^{\circ} 52\right.$ 'S e 645' W), 25-ix-1985, em lâmina. Parátipos 5 fềmeas (INPA-CR 607a e) e 2 fềmeas (MZUSP 10437a e b) todos em lâmina. Coletados por J. C. o. Malta.

Descrição da espécie: baseada em oito exemplares estudados e medidos (Tab. 1 e 2). Cefalotórax (Fig. 1 e Tab. 1) de forma ovóide, margem anterior reta alarga-se suavemente até chegar na região mediana, onde tem a largura máxima, cerca de 4 vezes a inicial, a partir deste ponto vai suavemente afilando-se até chegar na margem posterior do cefalotórax medindo acerca de 3 vezes a largura inicial. Tórax (Fig. I e Tab. 1) com 4 somitos livres que diminuem progressivamente de tamanho do somito III para o VI.

Abdômen (Figs. 1, 2 e 3 e Tab. 1) formado pelo somito genital duplo,

Tabela 1. Medidas (variaçäo e média em um) de 08 fêmeas adultas de Miracetyma piraya $\mathrm{sp} . \mathrm{n}$.

\begin{tabular}{lll}
\hline & \multicolumn{1}{c}{ Comprimento } & \multicolumn{1}{c}{ Largura } \\
\hline $\begin{array}{l}\text { Corpo } \\
\text { Cefalotórax }\end{array}$ & $978-1070(1026)$ & $352-473(403)$ \\
Somitos I e II & $618-680(638)$ & $352-473(403)$ \\
Somitos torácicos & & \\
$\quad$ III & $70-97(82)$ & $177-240(207)$ \\
IV & $72-85(78)$ & $142-195(165)$ \\
V & $37-57(49)$ & $100-152(123)$ \\
VI & $20-30(22)$ & $70-90(77)$ \\
Somito genital duplo & & \\
VII & $75-87(78)$ & $92-107(101)$ \\
Somitos abdominais & & \\
VIII & $10-15(12)$ & $52-72(65)$ \\
IX & $7-15(9)$ & $50-75(62)$ \\
X & $20-25(21)$ & $45-67(56)$ \\
Ramos caudais & & \\
$\quad$ XI & $35-37(36)$ & $27-37(32)$ \\
Saco de ovos & $269-474(397)$ & $70-97(82)$ \\
\hline
\end{tabular}

três somitos abdominais e os ramos caudais. Somito genital duplo (Figs. 1 e 2 e Tab. 1) hexagonal e com a largura máxima ocorrendo na região mediana. Somitos abdominais (Figs. 1, 2 e 3 e Tab. 1): somito 1 sem ornamentações, somito 2 com uma fileira de pequenos espinhos na margem posterior ventral; somito 3 (anal) com a região central da margem posterior côncava, com uma fileira de espinhos na margem posterior ventral, interrompida na regiäo central. Ramos caudais (Figs. 1, 2 e 3) retangulares, ambos equipados com uma seta longa e uma curta, duas setas reduzidas apicais e uma fileira obliqua de pequenos espinhos na margem subterminal posterior ventral.

Antênula (Fig. 4 e Tab. 2) reduzida, com cinco segmentos, setas simples e com a fórmula setal: $13-4$ - 4 - 2 - 6. Tipologia, comprimentos relativos e ornamentações diretamente comparáveis com a espécie-tipo. Antena (Fig. 5 e Tab. 2) com a característica garra reduzida, ranhura e as extensões cuticulares características do gênero. Apresenta três segmentos. Segmento 1 curto e com um espinho distal; segmento 2 muito longo, com uma extensão cuticular em toda a margem externa e em cerca de quatro quintos da interna; segmento $3 \mathrm{com}$ uma profunda ranhura na parte mediana da margem externa e uma extensão cuticular cobrindo três quartos do segmento, a margem posterior desta extensão é franzida, com 4 a 6 pregas terminalmente espiniformes; a garra é pequena e com uma bem definida ranhura na margem interna. A 


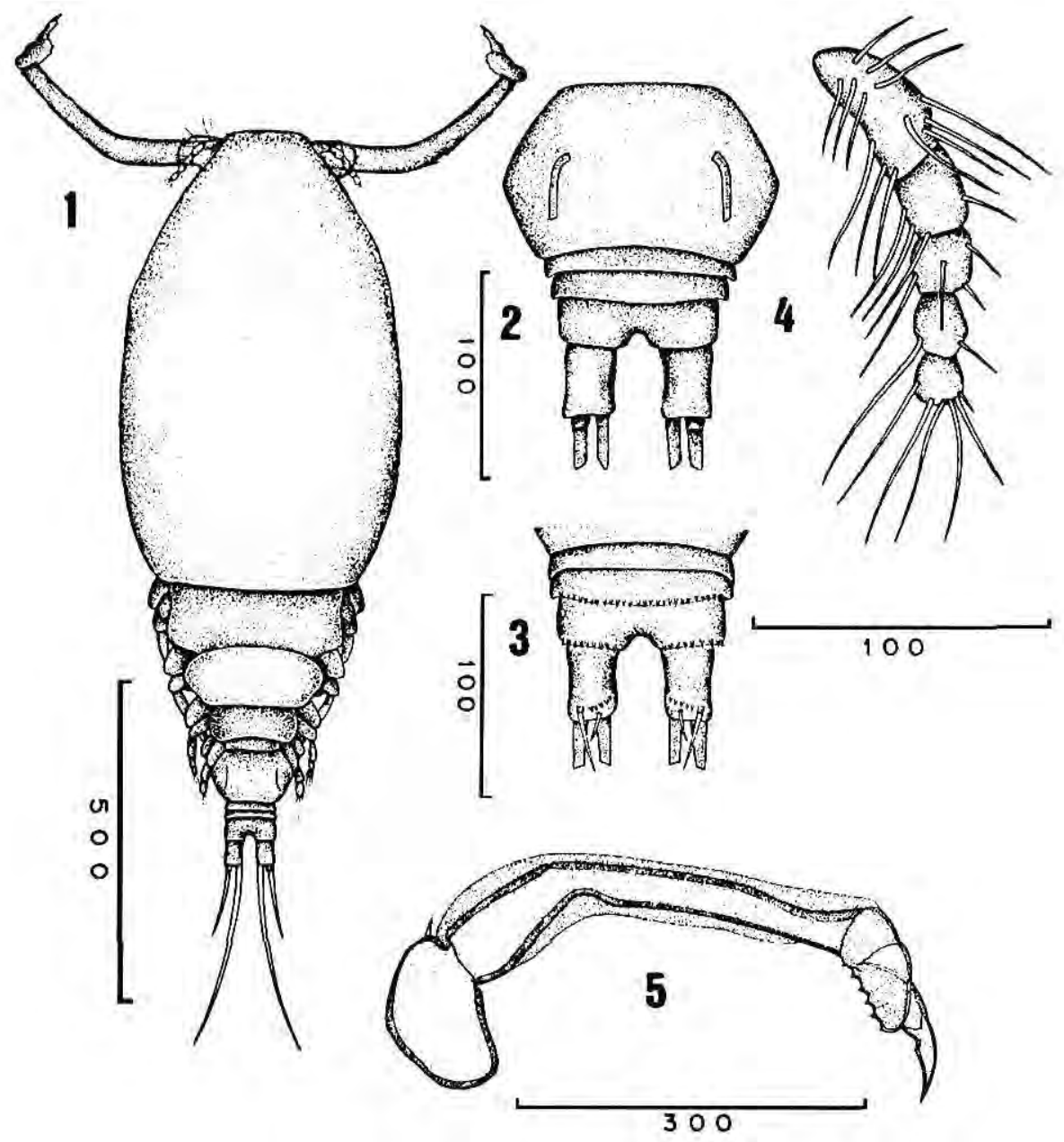

Figuras 1-5. Miracetima piraya sp. n. (fềmea) 1 - vista dorsal. 2 - somito genital duplo, abdômen e ramos caudais (vista dorsal). 3 - ramos caudais (vista ventral). 4 - antênula. 5 antena. 
Tabela 2. Medidas das antenas (variaçäo e média em um) de 08 fêmeas adultas de Miracetyma piraya $\mathrm{sp} . \mathrm{n}$.

\begin{tabular}{llll}
\hline & & Comprimento & \multicolumn{1}{c}{ Largura } \\
\hline $\begin{array}{l}\text { Antênula } \\
\text { Antena }\end{array}$ & $120-155(134)$ & $22-35(28)$ \\
Segmento & 1 & $95-114(104)$ & $52-77(62)$ \\
& 2 & $229-366(308)$ & $22-47(35)$ \\
& 3 & $82-111(92)$ & $22-37(31)$ \\
& Garra & $22-37(35)$ & $10-12(11)$ \\
\hline
\end{tabular}

relação entre os segmentos é 3,0:9,0 $2,5: 1,0$.

Peças bucais (Fig. 6): mandibula longa com uma base sub- retangular robusta, com uma protuberância proximal e outra mediana na margem anterior e afilando-se distalmente; lâmina falciforme com dentículos longos na margem posterior è um rebaixamento na margem anterior; na margem posterior do apêndice longo um palpo pequeno com uma série de dentículos na margem posterior. Maxílula muito pequena, em forma de placa, região anterior mais estreita, sem ornamentações. Maxila com uma base robusta e afilando-se distalmente, em sua margem posterior mediana um processo espiniforme, processo distal falciforme com setas espiniformes circundando as margens na região anterior.

Pernas (Figs. 7 - 10 e Tab. 3) providas de setas pectinadas; todos endopoditos mais longos que os exopoditos. Perna I (Fig. 7) com basipodito provido de um espinho na margem lateral externa. Endopodito com dois segmentos e exopodito com três. Endopodito extremamente modificado, muito grande e sem ornamentações; segmento 1 do endopodito, robusto, comprido e de forma irregu- lar, do mesmo comprimento e cerca de 2,0 vezes mais largo que o exopodito e com uma protuberância na margem externa distal; segmento 2 comprido e fino, 1,5 vezes mais longo e 2,5 vezes mais estreito que o exopodito. Segmentos 2 e 3 do exopodito com uma fileira de pequenos espinhos na margem externa. Segmento 1 sub-retangular medindo o dobro do tamanho do segmento 2 e com um espinho póstero-lateral; segmento 2 quadrangular e com uma seta; segmento 3 com cinco setas e dois espinhos.

Perna II (Fig. 8) semelhante à perna III, basipodito com um espinho na margem lateral externa. Ambos ramos com três segmentos. Segmentos 2 e 3 do endopodito, com uma fileira de pequenos espinhos na margem externa. Segmento 1 do endopodito robusto, medindo o dobro do comprimento do segmento 3 , sua largura é igual ao comprimento do segmento 3 e com uma seta lateral; segmento 2 robusto medindo uma vez e meia o comprimento do segmento 3 , da mesma largura do segmento 1 e com duas setas; o segmento 3 é afilado distalmente formando uma projeção espiniforme terminal e com quatro setas. Segmento I do exopodito robusto, largo, grande, sem ornamentações, medindo mais que o dobro do comprimento dos demais segmentos; segmento 2 quadrangular e com uma seta; segmento 3 triangular e com seis setas.

Perna IV (Fig. 9) endopodito com três segmentos, e exopodito com dois. Segmento 1 do endopodito subretangular medindo cerca de duas vezes 

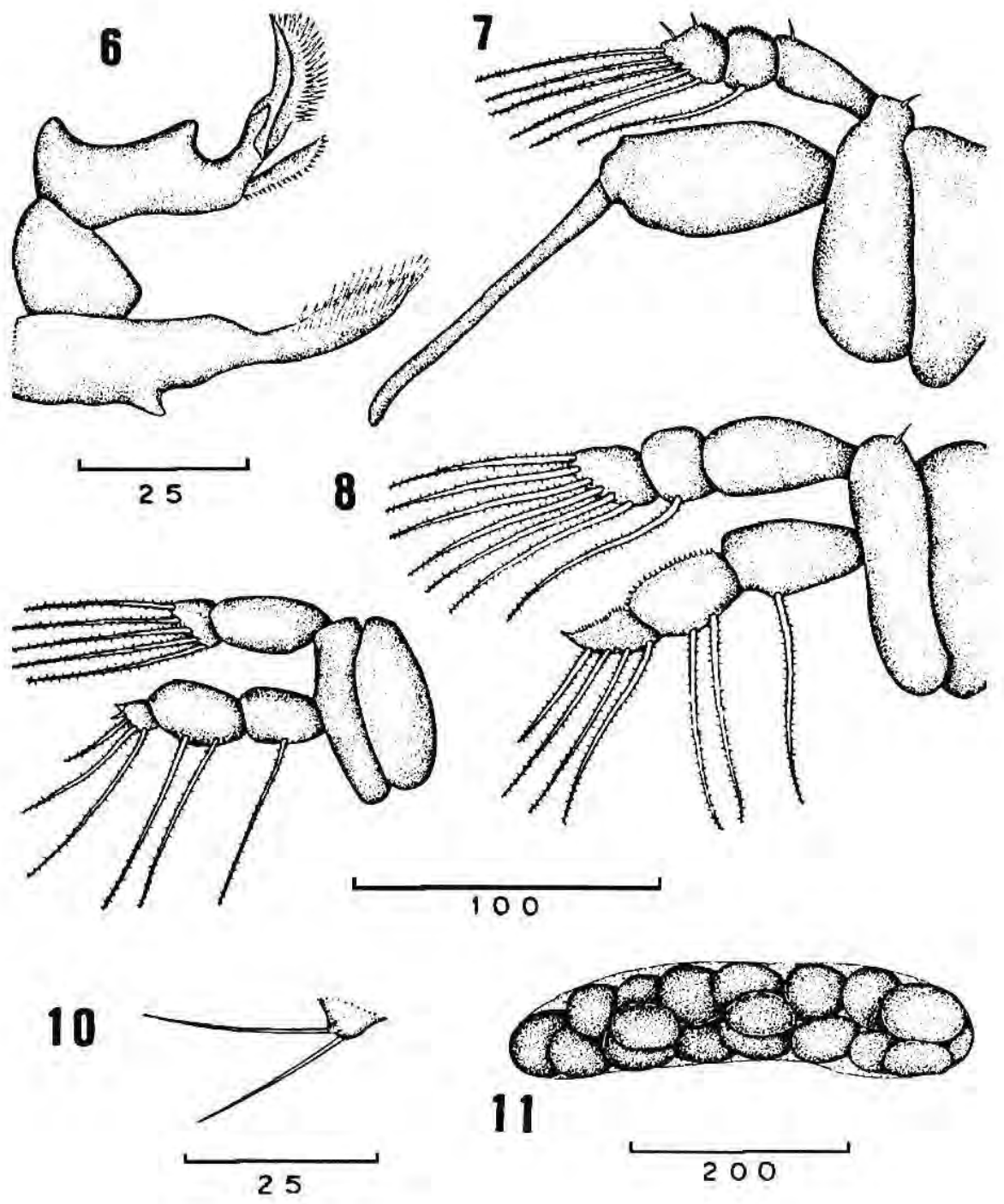

Figuras 6-11. Miracetima piraya sp. n. (fềmea). 6 - peças bucais. 7 - perna I. 8 - perna II (= perna III). 9 - perna 
o segmento 3 e com uma seta; segmento 2 sub-retangular medindo cerca de três vezes o segmento 3 e com duas setas; segmento 3 extremamente reduzido, afilado látero-distalmente formando uma projeção espiniforme, com três setas e um espinho. Segmento 1 do exopodito robusto, grande, subretangular cerca de três vezes maior que o segmento 2 e sem ornamentações; segmento 2 reduzido, triangular e com cinco setas. Perna V (Fig. 10) vestigial, consistindo de duas setas simples que se originam em papilas.

Saco de ovos (Fig. 11) com duas e três séries de ovos que variam numericamente, de nove a 17 .

\section{Macho: Desconhecido.}

Etimologia: O nome específico deriva do Tupi-Guarani: "pira"= peixe; "aya" = "ya" dente; dando origem a "piraya", que significa piranha, nome vulgar do hospedeiro.

\section{DISCUSSÃO}

Myracetyma piraya $\mathrm{sp} . \mathrm{n}$. é a terceira espécie conhecida do gênero, foi incluída neste grupo por apresentar o sistema de trava da antena e o tamanho e forma do primeiro endopodito característicos do gênero.

M. piraya $\mathrm{sp} . \mathrm{n}$. apresenta um tamanho e largura intermediários entre as duas espécies conhecidas, é maior e mais larga que $M$. etimaruya e menor e mais estreita que $M$. kawa Malta, 1993. Oformato do cefalotórax é ovóide enquanto que na espécie-tipo é hexagonal e na segunda espécie descrita arredondado.

O somito 2 do abdômen de $M$. piraya apresenta uma fileira de pequenos espinhos na margem posterior ventral, enquanto que nas outras duas espécies é liso.

A antena de $M$. piraya apresenta extensão cuticular: em toda a margem externa e em cerca de quatro quintos da interna do segmento 2 ; cobrindo três quartos do segmento 3 , a margem posterior da extensão é franzida e com 4 a 6 pregas terminalmente espiniformes. Enquanto que em $M$. kawa a antena apresenta uma extensão cuticular na margem interna e externa distal do segmento 2 e em $M$. etimaruya estas extensões ocorrem em toda a margem externa do segmento l e na margem interna do segmento 2 .

A maxílula de $M$. piraya não apresenta ornamentações como a de $M$. kawa, mas o formato é diferente. Em $M$. piraya a região proximal é mais estreita e a distal mais larga enquanto que em $M$. kawa é o inverso. Somente $M$. piraya apresenta um processo espiniforme na margem posterior mediana da maxila.

Características das pernas só encontradas em $M$. piraya: basipoditos das pernas I, II e III com um espinho na margem lateral externa; um espinho no segmento 1 e dois no segmento 3 do primeiro exopodito; formato irregular e uma protuberância na margem externa distal do segmento 1 do primeiro endopodito; segmento 3 do segundo e terceiro endopoditos afilados distalmente formando uma projeção espiniforme terminal; segmento 3 do 
quarto endopodito extremamente reduzido, afilado distalmente formando uma projeção espiniforme terminal e com três setas e um espinho.

$\mathrm{O}$ número de ovos em $M$. piraya é menor que nas outras duas espécies, varia de $9-17$ e arranjados em duas e três séries no saco ovígero. $\operatorname{Em} M$. kawa é maior, varia de $12-50$, arranjados em 3 e 4 séries e em $M$. etimaruya varia de $15-25$, arranjados em duas séries.

A espécie tipo do gênero Miracetyma, $M$. etimatuya foi coletada das brânquias de Curimata cyprinoides (Linnaeus, 1758), do rio Jamari, próximo à Ariquemes; de Potamorhina latior (Spix, 1829) dos rios Guaporé e Mamoré, próximo à Surpresa e Psectrogaster essequibensis (Gunther, 1864) do rio Pacaás Novos, próximo à Guajará-Mirim, todos os hospedeiros são da família Curimatidae e têm hábitos alimentares iliófagos. A segunda espécie $M$. kawa foi coletada das brânquias de Rhaphiodon vulpinus Agassiz, 1829 do rio Mamoré, próximos às localidades de Surpresa e Guajará-Mirim, do rio Guaporé próximo à Pimenteiras e do rio Jamari, próximo à hidrelétrica de Samuel, o hospedeiro é da família Cynodontidae e o hábito alimentar é carnívoro (MALTA, 1992, 1993a, 1993b).

A espécie descrita neste trabalho, M. piraya, foi coletada das brânquias de Pygocentrus nattereri, do Rio Mamoré, próximo a Surpresa o hospedeiro é da família Serrasalmidae e o hábito alimentar é carnívoro. Foi coletada na mesma localidade dos espécimens de $M$. imaruya de Psectrogaster essequibensis e seu hospedeiro tem o mesmo hábito alimentar que o de $M$. kawa.

Os índices que estimam o tamanho da população de $M$. piraya são: prevalência $8,0 \%$; intensidade 8 copépodos por peixe; intensidade média 8,0 e abundância 0,6 . Enquanto os de $M$. kawa são: prevalência $60,0 \%$; intensidade entre 1 - 34 copépodos por peixe; intensidade média 9,0 e abundância 6,0 e em $M$. etymaruya são: prevalência $39,5 \%$; intensidade entre 1 - 17 copépodos por peixe; intensidade média 4,0 e abundância 1,5 .

\section{Bibliografia citada}

HO, J. S. 1991. Phylogeny of Poecilostomatoida: a major order of symbiotic copepods, pp. 25-48 In: Proceedings of the Fourth International Conference on Copepoda, 9, 1990. S. UYE; S. NISHIDA, \& J.S. HO (eds) Karuizawa, Japão. Bull. Plankton Soc. Japan, Spec. Vol.

MALTA, J. C. O. 1992. Copépodos (Crustacea: Regasilidae) das brânquias de peixes do sudoeste da Amazônia Brasileira (Rondônia). Tese de Doutorado, Instituto de Biociências, Universidade Estadual Paulista, Rio Claro, São Paulo, 171 p.

1993a. Miracetyma etimaruya gen. et sp. nov. (Copepoda, Poecilostomatoida, Ergasilidae) from freshwater fishes of the Brazilian Amazon. Acta Amazonica, 23(1): 49-57.

1993b. Miracetima kawa sp. nov. (Copepoda, Poecilostomatoida, Ergasilidae) from freshwater fishes of the Brazilian Amazon. Acta Amazonica, 23(2/3): (no prelo). 
THATCHER, V. E. 1991. Amazon Fish Parasites, Amazoniana, $11(3 / 4)$ : 263-572.
VARELLA, A. M. B. 1992. Copépodos (Crustacea) parasitas das fossas nasais de peixes, coletados na regiāo de Rondônia, Brasil. Tese de Doutorado, Instituto de Biociências, Universidade Estadual Paulista, Rio Claro, São Paulo, $105 \mathrm{p}$. 